for use with measles vaccine $(0 \cdot 4-0 \cdot 8 \mathrm{IU} / \mathrm{kg}$ body weight; Blood Products Laboratory) was given in the opposite arm with a separate syringe immediately after the vaccine was injected. The measles haemagglutination inhibition antibody response was estimated in the paired sera by $\mathrm{MC}$ as described previously. ${ }^{4}$

\section{Results}

Antibody response-Figure 2 shows the haemagglutination inhibition antibody responses at eight weeks. One child (given Rimevax) failed to respond (titre $<4$ ) and two children had a minimal response $(4)$, one after Attenuvax and one after Mevilin.

Clinical reactions-Two reactions were reported after Rimevax. One child with left hemiplegia and a porencephalic cyst associated with dilatation of the right lateral ventricle had a fit five days after vaccination. This was not associated with fever and lasted for a few minutes during which his eyes rolled and he twitched; there had been no similar occurrence. He recovered immediately with no further episodes. Another child with microcephaly and cerebral palsy became febrile and irritable with a cough five days after vaccination but the next day was afebrile. Two children given Attenuvax were reported to have had rashes, one accompanied by coryza. No other reactions were reported.

\section{Discussion}

The 45 children in this study undoubtedly required protection from measles and because of their personal history were considered at risk of having a convulsion from a febrile response to the vaccine given alone. The one fit reported was not associated with fever and occurred in a child with a grossly abnormal brain. Clearly in this small study no unacceptable reactions occurred despite the increased risk.

Since it is not justifiable to take two blood samples from children routinely given measles vaccine any comparison of antibody response must be made with results from an earlier study. In a Medical Research Council trial in 1964,45 children aged 10 months to 2 years were bled before and after being given Schwarz strain vaccine. The response to the vaccine without immunoglobulin was significantly higher (5\% level or beyond), confirming that the antibody response is modified by immunoglobulin. All but one of the children in our study, however, produced a response; only clinical follow up will determine protection.

Modifying possible febrile reactions to further attenuated vaccines by using immunoglobulin is not considered necessary outside Britain. Nevertheless, if the current recommendation results in the vaccination of children such as these it seems justified, since without it they would have remained unvaccinated and at risk.

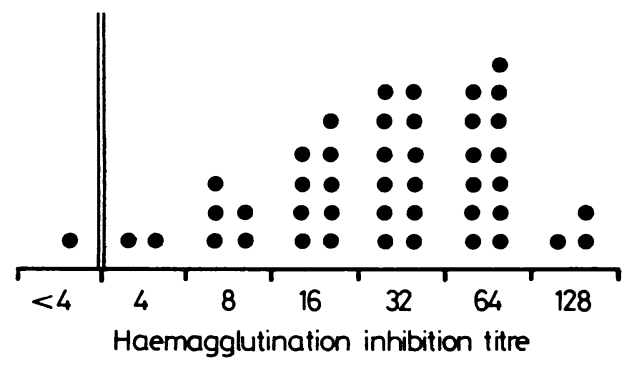

FIG 2-Measles haemagglutination inhibition antibody responses in children given measles vaccine with immunoglobulin.

The amount of specially diluted immunoglobulin for use with measles vaccine supplied by the Blood Products Laboratory trebled between 1983 and 1985, and discrepancies among vaccine manufacturers in the recommendations for its use and dosage have recently been eliminated. We hope that in future more children in these special categories will be vaccinated against measles.

\section{References}

1 Communicable Disease Surveillance Centre. Recommendations of Public Health Advisory Committee on immunisation practice. Morbidity and Mortality Weekly Report 1965 July 14:64.

2 Benson PF, Butler NR, Goffe AP, et al. Vaccination of infants with living attenuated measles vaccine (Edmonston strain) with and without gamma-globulin. Br Med f 1964;ii:851-3.

vepartment of Health and Social Security. Immunisation against infectious diseases. London: HMSO, 1984

4 Medical Research Council Measles Vaccination Committee. Vaccination against measles: a study of clinical reactions and serological response of young children. Br Med $\mathcal{F} 1965 ; 1: 817-23$.

(Accepted 11 March 1986)

\title{
Dose response of patients to oral corticosteroid treatment during exacerbations of asthma
}

\author{
JONATHAN R WEBB
}

\begin{abstract}
Ten patients with asthma were treated with different doses of oral corticosteroids during three separate exacerbations. Prednisolone was given in doses of $0.2,0.4$, and $0.6 \mathrm{mg} / \mathrm{kg}$ body weight daily for two weeks in a double blind randomised order (equivalent to 14, 28, and $42 \mathrm{mg}$ of prednisolone daily in a person weighing $70 \mathrm{~kg}$ ). Patients developing an exacerbation recorded peak expiratory flow rate twice daily for two days before starting and two weeks during treatment. A dose response was shown that was significant for the difference between the peak flows, low dose $<$ medium dose $(\mathbf{p}<\mathbf{0 . 0 0 5})$, medium dose $<$ high dose $(p<0.001)$ at the end of treatment.
\end{abstract}

Regional Respiratory Laboratory, Brook Hospital, London SE18 4LW JONATHAN R WEBB, MRCP, consultant physician
These results confirm the value of treatment with oral corticosteroids in exacerbations of asthma not requiring admission to hospital and indicate that a short high dose course of corticosteroids should consist of a minimum dose of $0.6 \mathrm{mg}$ prednisolone/kg body weight for a period up to two weeks.

\section{Introduction}

The value of treatment with corticosteroids in patients with asthma was first reported in $1949 .{ }^{1}$ There followed similar uncontrolled reports confirming their short term value. The Medical Research Council (MRC) published two controlled studies in $1956^{23}$; in one corticosteroid treatment for acute severe asthma was beneficial, but the second trial of treatment for chronic asthma over a period of six months showed that long term treatment with oral corticosteroids conferred no advantage. Other reports, however, showed that oral 
TABLE I-Patient details

\begin{tabular}{clccc}
\hline $\begin{array}{c}\text { Case } \\
\text { No }\end{array}$ & Age & $\begin{array}{c}\text { Age at } \\
\text { onset of } \\
\text { asthma }\end{array}$ & $\begin{array}{c}\text { Response to } \\
\text { bronchodilators } \\
(\%)^{\star}\end{array}$ & $\begin{array}{c}\text { Response to oral } \\
\text { corticosteroids } \\
(\%) \dagger\end{array}$ \\
\hline 1 & 53 & 32 & 57 & 51 \\
2 & 51 & 45 & 23 & 46 \\
3 & 40 & 23 & 18 & 59 \\
4 & 48 & 48 & 31 & 221 \\
5 & 48 & 47 & 31 & 99 \\
6 & 54 & 52 & 41 & 62 \\
7 & 61 & 57 & 28 & 157 \\
8 & 71 & 68 & 36 & 78 \\
9 & 53 & 52 & 57 & 93 \\
10 & 57 & 56 & $40 \cdot 1$ & $89 \cdot 3$ \\
\hline Mean & $53 \cdot 6$ & $48 \cdot 0$ & & \\
\hline
\end{tabular}

$\star \%$ Improvement in peak expiratory flow rate before and after inhaled $\beta_{2}$ stimulants (pressurised aerosol) in the morning (average of one week's recordings).

t\% Improvement in peak expiratory flow rate after two weeks' treatment with prednisolone $0.6 \mathrm{mg} / \mathrm{kg}$ (calculated from table II)

TABLE II-Mean peak expiratory flow rate before $e^{\star}$ and aftert treatment

\begin{tabular}{|c|c|c|c|c|c|c|}
\hline \multirow{3}{*}{$\begin{array}{c}\text { Case } \\
\text { No }\end{array}$} & \multicolumn{6}{|c|}{ Prednisolone } \\
\hline & \multicolumn{2}{|c|}{$0.2 \mathrm{mg} / \mathrm{kg}$} & \multicolumn{2}{|c|}{$0.4 \mathrm{mg} / \mathrm{kg}$} & \multicolumn{2}{|c|}{$0.6 \mathrm{mg} / \mathrm{kg}$} \\
\hline & Before & After & Before & After & Before & After \\
\hline 1 & 202 & 417 & 298 & 440 & 272 & 410 \\
\hline 2 & 148 & 187 & 157 & 224 & 172 & 251 \\
\hline 3 & 269 & 399 & 255 & 359 & 261 & 414 \\
\hline 4 & 216 & 325 & 143 & 295 & 137 & 440 \\
\hline 5 & 295 & 467 & 314 & 455 & 253 & 503 \\
\hline 6 & 299 & 356 & 262 & 354 & 250 & 318 \\
\hline 7 & 162 & 312 & 165 & 339 & 205 & 332 \\
\hline 8 & 137 & 257 & 119 & 308 & 148 & 380 \\
\hline 9 & 170 & 249 & 211 & 308 & 173 & 308 \\
\hline 10 & 137 & 210 & 159 & 306 & 152 & 293 \\
\hline Mean & 203.5 & 317.9 & $208 \cdot 3$ & 338.8 & $202 \cdot 3$ & 364.9 \\
\hline
\end{tabular}

$\star$ Before treatment $=$ mean of five peak expiratory flow rate readings on days 1,2 , and morning of day 3.

tAfter treatment $=$ mean of peak expiratory flow rate readings over last four days of treatment

\section{Patients and methods}

A randomised double blind study was performed giving three different $\stackrel{\text { W }}{\underline{T}}$ doses of oral corticosteroids to each patient during three separate exacerba- $\frac{3}{8}$

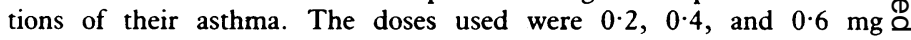
prednisolone $/ \mathrm{kg}$ body weight as a single morning dose daily for two weeks $c$ (equivalent to 14,28 , and $42 \mathrm{mg}$ prednisolone in a $70 \mathrm{~kg}$ person). The three $\widehat{\widehat{\Omega}}$ courses of prednisolone looked identical to the patient and consisted of $\overline{\bar{\Xi}}$ varying combinations of active and placebo tablets, which the pharmacist 7 prepared on the basis of the patient's weight.

Patients kept a Wright mini peak flow meter at home and began recording their peak expiratory flow rate whenever they began to experience 0

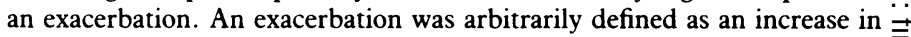
symptoms despite increased use of inhaled $\beta_{2}$ stimulants accompanied by a $\Omega$ drop in their usual peak flow rates. Patients recorded peak expiratory flow $\overline{0}$ rates twice daily, first thing in the morning after getting out of bed and last $\frac{D}{0}$ thing at night before going to bed. Patients contacted me at the start of an $\overline{\bar{N}}$ exacerbation and were seen soon afterwards. A course of corticosteroids was $\vec{\nabla}$ prescribed if the exacerbation was thought to warrant treatment with $\varnothing$ corticosteroids. The patients continued to record their peak expiratory flow is rate for the two weeks' duration of treatment. The patients had at least two $\vec{A}$ days' recordings of peak expiratory flow rates before they began treatment with corticosteroids.

All patients were treated with inhaled salbutamol $200 \mu \mathrm{g}$ four times daily, $\stackrel{\omega}{\sigma}$ and the dose was boosted to $200 \mu \mathrm{g}$ two hourly if required. Two patients $O$ were taking low dose beclomethasone dipropionate $0.4 \mathrm{mg} / \mathrm{day}$ and two others slow release aminophylline preparations.

\section{Results}

Details of the patients are given in table I and show that eight of the patients had asthma of late onset (age at onset $>45$ years). Tat/le II shows the $\mathrm{G}$ individual peak expiratory flow rates tefore and over the last four davs of $\frac{}{\supset}$ treatment for the three treatments. There were no significant differences in $\vec{\varphi}$ morning or evening peak expiratory flow rate for all patients before receiving the three doses of prednisolone.

The figure gives the results, expressed as the mean peak expiratory flow rate for the group of 10 patients; both the morning and evening peak $\overrightarrow{0}$ expiratory flow rates for the three doses of prednisolone are given. By the end $\stackrel{\infty}{\infty}$ of the treatment period a dose response effect became apparent. Over the last four days all peak expiratory flow rates for the medium dose $(0.4 \mathrm{mg} / \mathrm{kg}$ body

TABLE III-Comparison of mean morning and evening peak expiratory flow rates combined and mean morning peak expiratory flow rate alone with dosage of corticosteroid treatment received during the last four days of treatment (paired $t$ test)

\begin{tabular}{|c|c|c|c|c|c|c|}
\hline Corticosteroid treatment & $\begin{array}{c}\text { Mean morning and evening } \\
\text { peak expiratory flow rate combined } \\
(1 / \mathrm{min})\end{array}$ & $\mathrm{SEM}^{\star}$ & $\mathrm{p}$ Value & $\begin{array}{c}\text { Mean morning } \\
\text { peak expiratory flow rate } \\
(\mathrm{l} / \mathrm{min})\end{array}$ & $\mathrm{SEM}^{\star}$ & $\mathrm{p}$ Value \\
\hline Low dose $(0 \cdot 2 \mathrm{mg} / \mathrm{kg})$ & $317 \cdot 5$ & & & $279 \cdot 5$ & & \\
\hline Medium dose $(6.4 \mathrm{mg} / \mathrm{kg})$ & $338 \cdot 3$ & & & $307 \cdot 4$ & $11 \cdot 08$ & $<0.02$ \\
\hline High dose $(0.6 \mathrm{mg} / \mathrm{kg})$ & $364 \cdot 8$ & $7 \cdot 38$ & $<0.001$ & $345 \cdot 7$ & $9 \cdot 74$ & $<0.001$ \\
\hline
\end{tabular}

* Standard error of the difference between the means.

corticosteroids were of value in the treatment of chronic asthma ${ }^{+6}$ and this view has prevailed. The value of corticosteroid treatment in acute severe asthma has recently been reinvestigated in more detail, and the original findings of the MRC have been confirmed.?

The introduction of inhaled corticosteroids has meant that many patients with chronic asthma are now managed with long term inhaled corticosteroids rather than continuous treatment with oral corticosteroids. Although it is common practice to treat exacerbations of asthma with oral corticosteroids on an outpatient basis, there is little published work on the use of this drug in asthmatic patients. Fiel et al showed an advantage in giving oral corticosteroids to patients with attacks of asthma who were treated in an accident and emergency department and subsequently sent home. ${ }^{8}$

This study was designed to investigate the dose response of patients to a short course of treatment with oral corticosteroids during exacerbations of asthma. The criteria for a diagnosis of asthma included the presence of airflow obstruction, a history suggestive of asthma, and a response to treatment with both bronchodilators and oral corticosteroids (see table I). weight) were higher than the values for the low dose $(0.2 \mathrm{mg} / \mathrm{kg})$ and all the high dose $(0.6 \mathrm{mg} / \mathrm{kg})$ peak expiratory flow rates were higher than those for $\mathrm{G}$ the medium dose (table III). These differences were significant for the morning and evening peak expiratory flow rates combined and for the morning peak expiratory flow rate alone but did not reach significance for the $N$ evening peak expiratory flow rate, over the last four days.

All peak expiratory flow rates during the three treatments showed a similar pattern of diurnal variation, all the morning peak expiratory flow rates are represented by the trough values and the evening peak expiratory $\stackrel{\varrho}{\subset}$ flow rates by peak values. There was a trend towards improvement $\mathbb{\Phi}$ throughout the two week treatment period, and in none of the six graphs? does an obvious plateau occur, though the graphs for high dose peak 0 expiratory flow rate do show a trend towards a plateau of response over the $\frac{0}{\mathbb{\Phi}}$ last four days of treatment.

The individual responses were assessed by inspecting the peak expiratory $\mathbb{D}$ flow rate graphs for all 30 treatments $(10$ patients each having three treatments). The time taken to reach a plateau of response was assessed by eye in all cases, and in three courses a plateau was not obviously reached by $\delta$ the end of treatment. The mean time taken to reach a plateau at all three doses was virtually identical, at $10 \cdot 2$ days for low dose treatment, 10.2 days for medium dose, and 10.0 days for high dose (the time taken to reach a 


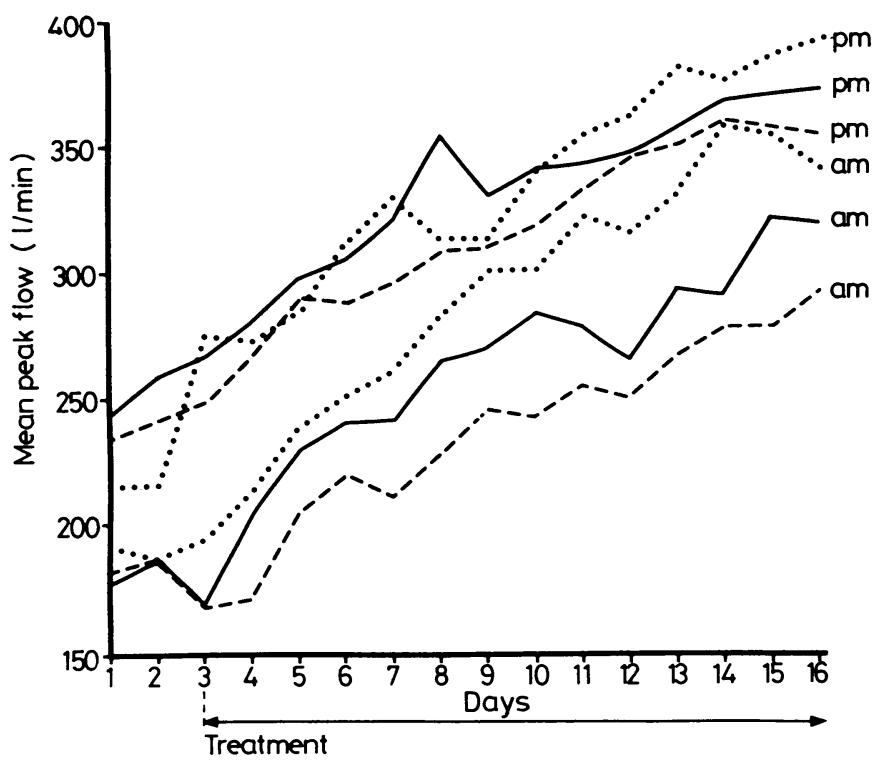

Peak flow chart for morning (am) and evening (pm) peak expiratory flow rates during three courses of prednisolone treatment. Low dose $(--)=0.2 \mathrm{mg}$ prednisolone $/ \mathrm{kg}$ body weight; medium dose $(-)=0.4 \mathrm{mg} / \mathrm{kg}$; high dose $(\cdots)=0.6 \mathrm{mg} / \mathrm{kg}$

plateau in the three cases in which a plateau was not actually achieved was taken to be 14 days)

\section{Discussion}

Ethical considerations and a proved dose response effect obviate the need for a control group and show that treatment with corticosteroids were of value in this group of patients.

This study did not show the dose required to produce the maximum effect - that is, the top end of the dose response curve. Britton $e t$ al showed in patients with severe acute asthma that there is no advantage in using a dose greater than $80 \mathrm{mg}$ prednisolone daily for seven days with a reduction to $60 \mathrm{mg}$ daily for three days. ${ }^{9}$ As the pharmacokinetics of prednisolone are dose dependent but not linear it is necessary to more than double the dose to achieve twice the effect. ${ }^{10}$ The top end of the dose response curve probably lies between $40 \mathrm{mg}$ and $80 \mathrm{mg}$ daily (about $0.6 \mathrm{mg} / \mathrm{kg}$ body weight and $1.2 \mathrm{mg} / \mathrm{kg}$ ), and in view of the above comments on the pharmacokinetics is probably nearer $40 \mathrm{mg}$. The mechanism of action of corticosteroid treatment in asthma is poorly understood, but it may be possible to extrapolate from the results of use of prednisolone in immune suppression after renal transplantation. Papadakis et al showed that $0.6 \mathrm{mg}$ prednisolone $/ \mathrm{kg}$ body weight was just as effective as much higher doses of corticosteroids for preventing the rejection of cadaveric kidneys. ${ }^{11}$

Although the group data did not clearly show a plateau, analysis of the individual data suggests that a plateau had been reached by 14 days' treatment as a plateau was seen by eye in 27 of the 30 courses. The duration of treatment in this study was too short to show if a plateau of response had or had not occurred in three of the courses of treatment. The average duration of 10 days to achieve a plateau for all three doses suggests that the time course is not dose dependent. The time course of the response is probably dependent on the clinical state of the patient, patients with exacerbations of chronic asthma requiring more time to achieve a maximum response than the same patients during remission. This is supported by findings of a previous study, which showed the time course of the response to oral corticosteroid treatment in patients with chronic airflow obstruction who were not experiencing an exacerbation. ${ }^{12}$ The results for the group showed a plateau occurring at eight days, and the average duration of response was $5 \cdot 1$ days (calculated from Webb and Clark ${ }^{12}$ ).

The absolute diurnal variation did not alter significantly over the two weeks' treatment (figure). The improvement in morning peak expiratory flow rate paralleled the improvement in evening peak expiratory flow rate so that the absolute morning dip improved but diurnal variation did not. Munch et al showed that nocturnal symptoms improve with regular inhaled steroids, ${ }^{13}$ and this study supports their findings.

Prednisolone was given as a single morning dose rather than in divided doses, two, three, or four times daily for three reasons. ${ }^{10}$ Firstly, the plasma half life of the prednisolone is $2-3$ hours and a morning dose coincides with peak activities of circulating adrenocorticotrophic hormone, thus inhibition of this hormone is minimised. Secondly, the biological half life of prednisolone is 24-36 hours, which suggests that a dose given more often than once daily is unnecessary. Finally, the protein binding capacity of transcortin, the steroid carrier protein, is weakest during the day, resulting in high concentrations of free unbound steroid.

The practice of tailing off corticosteroid treatment was introduced in the mid-1950s, ${ }^{14}$ and is still widely practised. This was presumably thought to aid the recovery of the hypothalamicpituitary-adrenal axis and to prevent any rebound increase in asthma. There is no supportive evidence that a short course of high dose corticosteroids causes clinically significant depression in the hypothalamic-pituitary-adrenal axis ${ }^{15}$ or that there is any rebound phenomenon after a short high dose course of corticosteroids. It seems more sensible to administer a dose of oral corticosteroids that has a maximum effect and to continue treatment at that dose until the patient has reached a plateau of improvement.

In conclusion, a short high dose course of corticosteroids should usually consist of a minimum dose of $0.6 \mathrm{mg} / \mathrm{kg}$ body weight/day for a period of up to two weeks.

I thank Professor Tim Clark for his helpful criticism during the preparation of this article and Mrs Joan Major for typing the manuscript.

\section{References}

1 Bordley JE, Carey RA, Harvey AM, et al. Preliminary observations on the effect of adrenocorticotropic hormone (ACTH) in allergic diseases. Bulletin of the-fohns Hopkins Hospital 1949;85:396-8.

2 Medical Research Council. Controlled trial of effects of cortisone acetate in status asthmaticus. Lancet 1956;ii:803-6.

3 Medical Research Council. Controlled trial of effects of cortisone acetate in chronic asthma. Lancet 1956;ii:798-803.

4 Phear D, Ball K, Page F. Prolonged treatment with steroids in severe chronic asthma. Lance 1960;i:139-41.

5 Grant IWB. Corticosteroids in asthma. Br Med $\mathcal{J} 1961 ;$ ii: 1781

6 Rees HA, Williams DA. Long term steroid therapy in chronic intractable asthma. $\mathrm{Br} \mathrm{Med}$ $1962 ;$ i: $1575-9$.

7 Fanta CH, Rossing TH, McFadden ER. Glucocorticoids in acute asthma. Am $\mathcal{J}$ Med 1983;74 $845-51$.

8 Fiel SB, Swartz MA, Glanz K, Francis ME. Efficacy of short-term corticosteroid therapy in outpatient treatment of acute bronchial asthma. Am f Med 1983;75:259-62.

9 Britton MG, Collins JV, Brown D, Fairhurst NPA, Lambert RG. High-dose corticosteroids in severe acute asthma. $\mathrm{BrMed}$ 1976;ii:73-4.

10 Clark TJH, Godfrey S, eds. Corticosteroids in asthma. London: Chapman and Hall, 1983.

11 Papadakis J, Brown CB, Cameron JS, et al. High versus "low" dose corticosteroids in recipients of cadaveric kidneys: prospective controlled trial. Br Med f 1983;286:1097-100.

Webb J, Clark TJH, Chilvers C. Time course of response to prednisolone in chronic airflow obstruction. Thorax 1981;36:18-21.

13 Munch EP, Taudorf E, Weeke B. Dose frequency in the treatment of asthmatics with inhaled topical steroid. Eur J Respir Dis 1982;63(suppl 122):143-53.

14 Anonymous. Corticosteroid therapy in asthma [Editorial]. BrMed f $^{0} 0$ ? : ii: 1413-4.

15 Webb JR, Clark TJH. Recovery of plasma corticotrophin and cortisol levels after a three week course of prednisolone. Thorax 1981;36:22-4

(Accepted 4 March 1986) 